\title{
Pre-scheduled load shutdown in microgrid utilizing computerized surveillance system
}

\author{
Bhagyashri.S ${ }^{1}$, Kanimozhi.G ${ }^{2}$, Umamaheswari.E ${ }^{3}$, Devi Mani ${ }^{4}$, Anitha.R. ${ }^{5}$ \\ ${ }^{1,2,3}$ School of Electrical Engineering, VIT University, India \\ ${ }^{1,2,3}$ School of computing science and Engineering, VIT University, India \\ ${ }^{4,5}$ Department of computer Science, King Khalid University, Saudi Arabia
}

\begin{tabular}{l} 
Article Info \\
\hline Article history: \\
Received Nov 17, 2018 \\
Revised Jan 7, 2019 \\
Accepted Mar 14, 2019 \\
\hline Keywords: \\
Distributed generation \\
Internet of things (IoT) \\
Load shedding \\
Microgrids \\
Time scheduling
\end{tabular}

Corresponding Author:

Kanimozhi.G, School of Electrical Engineering, VIT University, Chennai.

Email: kanimozhi.g@vit.ac.in

\begin{abstract}
The successful inclusion of microgrids for enhancement of the existing power system is laden with many challenges. Increase in demand and insufficient power generation results in power shutdown in several areas which comprises non-critical loads. The preface of Distributed Generation (DG) in power system has varied implications on the existing system. The concept proposed in this paper helps in time scheduling and load scheduling of a power system based on priority setting and time setting. The load management may also be done using IoT which enables load shedding from remote areas.
\end{abstract}

Copyright $(2019$ Institute of Advanced Engineering and Science. All rights reserved.

\section{INTRODUCTION}

In a developing country like India where there is rapid population growth, increasing elec-trical power demand is a critical issue. The most important issues which need to be addressed immediately are the increasingly depleting conventional energy resources, high emissions of car-bon dioxide gas, and the ever growing rates of electrical power due to the increase in power demand [1]. As a result, DGs and microgrids are becoming prevalent in the recent days replacing the centralized power plants and thus reducing the loss of power during transmission. However, this leads to several new challenges concerning power system instability and fluctuation. When a power system is not able to cater to the loads due to a generator shutdown or due to a tie line being open, the voltage and frequency of the system go below the specified limits. The imbalance between the amount of generated power and the power demand leads to frequency instability which enforced in blackouts in microgrids. To overcome this problem, load shedding is performed [2]. Load shedding is the process carried out by electric utilities when there is an extremely high demand for electricity which exceeds the generation. Load pre-scheduling is done which prior-itizes the load to be shut down based on the consumer's priority depending on the nature and importance of the loads. For example, the loads which get affected the most due to frequency fluctuations such as single phase motors is shut down first [3] where the loads that need a very stable power supply like industrial furnaces used in processing should be disconnected last. A load shedding schedule followed by every power system based on the nature of disturbance and also the type of loads connected and their importance.

This paper proposes a methodology for the implementation of automatic load shedding in microgrids using programming techniques [4-5]. Whenever a power system is not able to supply its loads due to shut down of generator or an open tie line, load shedding schemes is used to reduce the quantity of loads to 
a lower level which is comfortably supplied by the power generated till the disturbance is rectified. The proposed system disconnects the respective loads based on the load shedding schedule prepared in accordance with the consumers priority [6-7]. Furthermore, load is cut off and the duration of its shut down is made available to the users using Internet of Things (IoT).

The three main factors of load shedding are the location of load shed, delay and number of loads. One reason for delay in load shed is to ensure that the system is indeed unstable and hence load shedding cannot be avoided. And it is important to identify the optimal load shedding location.

\section{MICROGRID AND DISTRIBUTED GENERATION}

The advancement of technology [8-11] has led to numerous power generation tech-niques. These power generation techniques either utilize renewable resources such as wind, solar, tidal, geothermal etc or conventional non-renewable resources such as coal, nuclear en-ergy etc. The implementation of microgrids in urban areas has led to preface of DG. There are two types of DG in micro grids, one being islanded connection where the generated electricity is not connected to the grid while the other type is grid connected. When demand is more than generation, grid supplies the electricity to meet the load side demand. While generation is more than the demand, the electricity is supplied to the grid. As a result, the power flow in the system is no longer unidirectional, when grid connected.

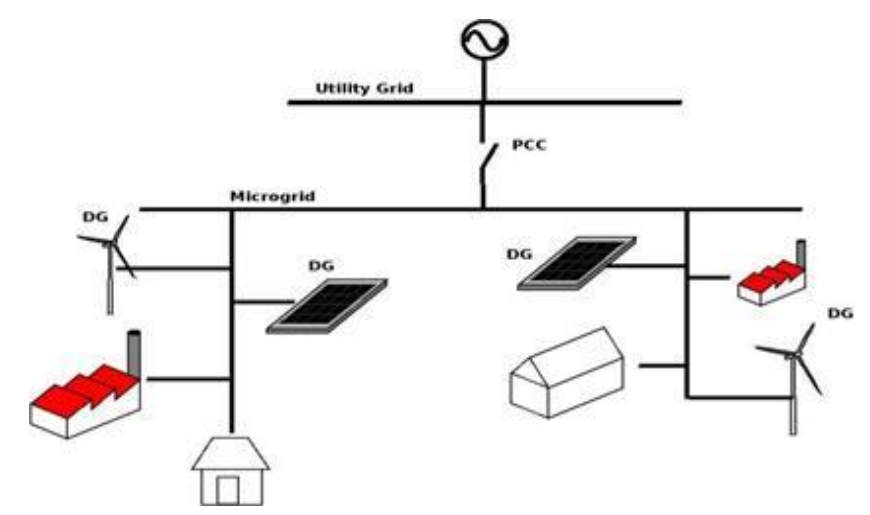

Figure 1. Microgrid structure

The interface switch or Point of Common Coupling (PCC) is used to connect and discon-nect the DG's whenever required. Microgrid comprises of DGs, controllable loads and storage devices. The power produced is transmitted, consumed and managed in a local scale. Microgrids provides energy backup to the grid during demand and improves the power quality, enhances energy efficiency by increasing system reliability with reduced cost. It plays a vital role in reducing greenhouse gases by using renewable energy sources for generating electricity. Diagrammatic model of microgrid is represented in Figure 1.

DGs are mostly renewable energy sources, such as PhotoVoltaic (PV) array, wind tur-bines, etc. The DGs usually has minimal cost, high reliability and low voltage. Voltage output differs from time to time according to the climatic changes. Hence an intermediate power elec-tronic device (such as boost converter and regulator) is required to provide regulated input to the loads. Figure 2 is the representation of DG with the load. Distributed cogeneration where the heat produced during the generation of electricity is utilized for heating and cooling purposes in house-holds. This allows utilisation of resources judiciously without any wastage and efficient utilisation of energy. The distributed cogeneration schematic is represented in Figure 3.

Super-capacitor, batteries at the DC bus or direct association of AC storage device such as flywheel are commonly used as the storage devices. During islanded operation, Distributed Storage (DS) in microgrids faces transients. DS should be capable of providing electricity to load when the microgrid is not grid connected. The DS must not only store energy, however should also give steady power required to strike a balance between energy generation and consumption, when there are disturbances or significant load change. The microgrid must be able to meet both electrical and thermal load requirements [3]. The distributed cogeneration scheme helps to utilize both electrical and thermal power generated. Figure 4 shows the radial feeders consisting of critical and non-critical loads. The feeder B without the DG is a noncritical load, whereas feeder A and C with DG are critical loads. All critical loads require a renewable source to continuously supply energy. 


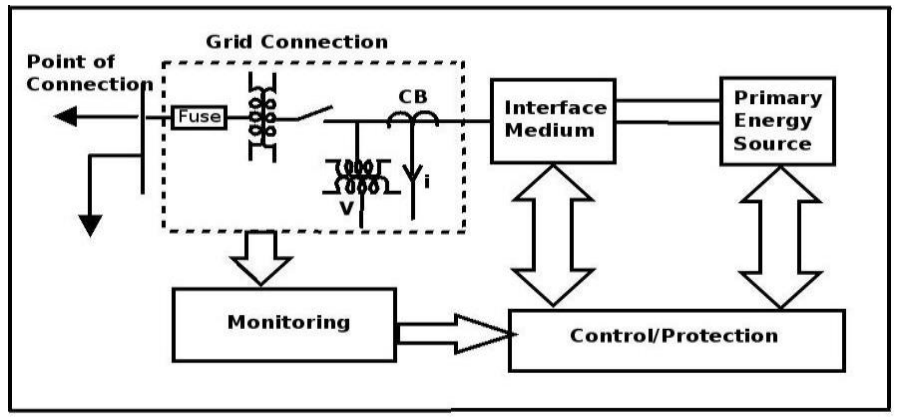

Figure 2. DG units in block representation

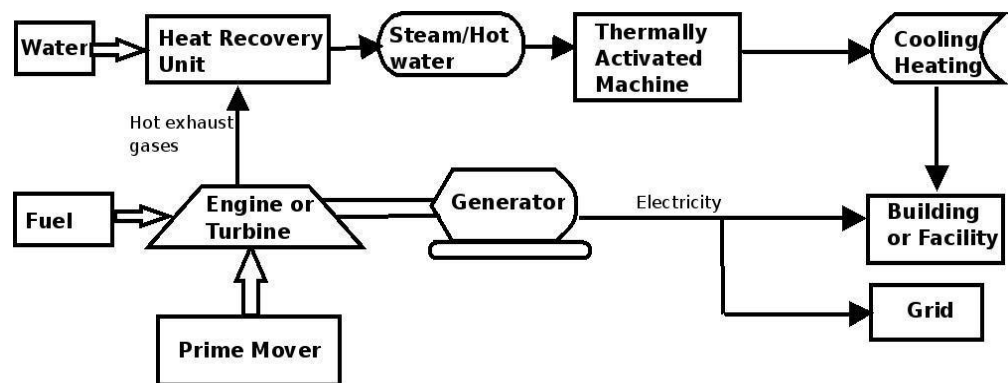

Figure 3. Distributed Cogeneration

All critical feeders represented in the Figure 4 requires reliable micro source to continuously supply energy.

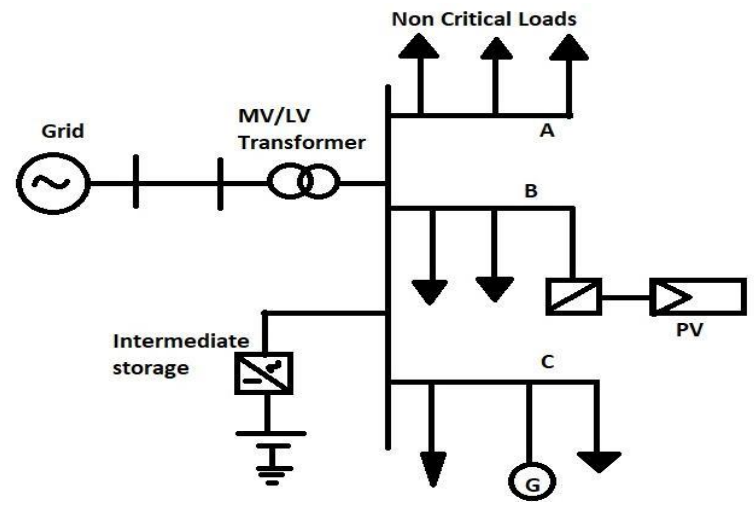

Figure 4. Feeder in typical microgrid

\section{CONTEGENCY ANALYSIS IN A GRID [12-22]:}

Studying thousands of possible outages becomes very difficult to solve in case of rapid results. Sometimes due to line outages, scheduled generation is applied to the system. One of the easiest way to provide rapid calculation of possible overload condition is to use linear sensitivity factors. Linear sensitivity factors ali are given by:

$$
a l i=\frac{\Delta f_{l}}{\Delta P_{i}}
$$


where $l=$ line index; $i=$ bus index; $\Delta P_{i}=$ change in generation in bus $i$ and $\Delta f_{l}=$ Change in megawatt power flow in line $l$ when change in generation occurs in bus $i$.

It is assumed that the change in generation $\Delta P_{i}$ is exactly compensated by an opposite change in generation at the reference bus and all other generators remain fixed. The factor ali represents the sensitivity of the flow on line 1 to a change in generation at bus $i$.

$$
\Delta P_{i}=-P_{0}
$$
follows:

Using pre-calculated generation shift factors, post contingency line flows can be obtained as

$$
\wedge_{f_{l}}=f_{l}^{\circ}+\left(\text { ali } * \Delta P_{i}\right)
$$

Where, ${ }^{\wedge} f_{l}=$ post contingency flow on line 1 after generator on bus I fails; $f_{l}^{\circ}=$ flow before the failure or contingency. The line outage distribution factors are used in a similar manner, applied for overloads when transmission circuits are lost. By definition, the line outage distribution factor has.

$$
d_{l, k}=\frac{\Delta f_{l}}{f_{k}^{\circ}}
$$

where, $d_{l, k}=$ line outage distribution factor when monitoring line $l$ after an outage on line $k ; \Delta f_{l}$ change in MW flow in line $l ; f_{k}^{0}=$ original flow in line $k$ before outage. If the power on line $l$ and line $k$ is known, the flow on line $l$ with line $k$ out can be determined using $\mathrm{d}$ factors.

$$
\wedge_{l}=f_{l}^{\circ}+\left(d_{l, k} * f_{k}^{\circ}\right)
$$

Where, $f_{l}^{\circ}, f_{k}^{\circ}=$ pre-outage power flow in line $l$ and $k$ respectively; ${ }^{\wedge} f_{l}=$ post contingency flow on line $l$ with line $k$ out. By pre-calculating the line outage distribution factors, a fast procedure can be set up to test all lines in the network for overload for the outage of a particular line. Furthermore, this procedure can be repeated for the outage of each line in turn, with overloads reported to the operations personnel in the form of alarm messages.

\section{PROGRAMMABLE LOAD SHEDDING}

The programmable load shedding [20-22] is carried out using Arduino. The safety of the system is taken into consideration and a system security password is programmed to restrict the accessibility. If the password does not match, the proceedings are aborted. If the password matches the password set, the program allows selecting the time after which the circuit breaker should be opened. The circuit breaker is activated after the specific time delay and it is tested using a relay and a load. The date, time, day of circuit breaker action is monitored. A real time clock (RTC) is used to match the operating time with real time and notify the users about the duration for which the load is disconnected. The authorities can enter the time values as ON and OFF periods for each load using the matrix keypad. The flowchart representation of the circuit breaker monitoring is represented in Figure 6. IoT may also be carried out using ESP8266 module and think speak platform. The API key is matched and the circuit breaker action is monitored using mobile phone. Implementation of IoT is explained in Figure 5. 
Preferential load shedding with time delay and appropriate security is accomplished in the proposed model. Load shedding during peak hours using automatic preferential scheme is applied in the above mentioned model. The password security scheme prevents unauthorized access and enforces safety. Time delay is set to trip the relay and shed the load at the peak demand. The time and date of circuit trip is noted using the RTC module. Figure 7 shows the recorded circuit breaker operation. This type of model further helps in preferential load shedding. Differentiating the loads into critical, semi critical loads and shutting them off according to the preference during the peak demand situation helps to conserve power.

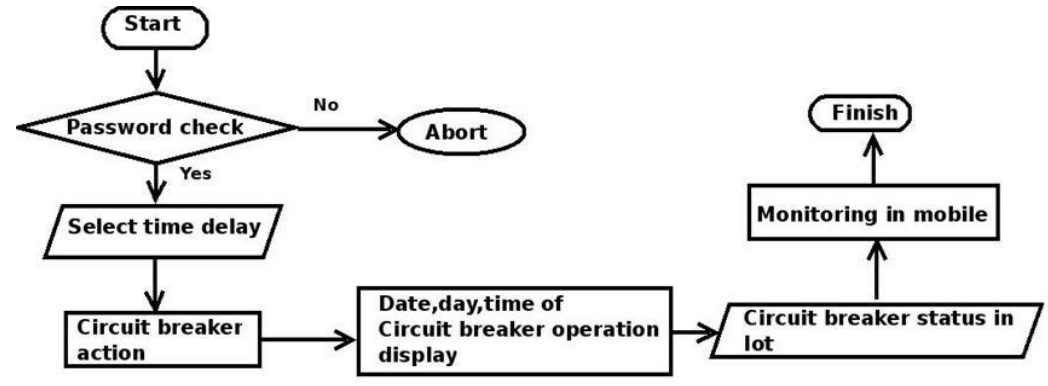

Figure 5. Implementation of IoT on microgrid

\section{EXPERIMENTAL VERIFICATION}

The project is designed to operate an electrical load multiple number of times as per the program. It overcomes the difficulties of switching the load ON/OFF manually. The various hardware components used in this model are listed in Table 1. An inbuilt RTC is included to keep track of the time and thus to switch ON/OFF the load accordingly. The RTC is a low power device that shows the real time at every instant. It can operate both in 12-hour and 24-hour format and has a battery backup. Once the RTC is programmed, it will work continuously even if the power goes off in between. It uses I2C two wire interface and has a provision to store data as well. The Matrix keypad allows users to enter time values for each load as on and off periods. It is one of the most common input devices used for microcontroller based applications.

The system uses Arduino Uno board which is chosen owing to its cost effectiveness and sustainability. It has a high clock speed and offers faster debugging provision and can also be powered without an external power source. Arduino stores the values entered through keypad and executes them by comparing with the timer clock provided by the RTC. As the time matches, the Arduino sends command signals to a relay driver that drives different loads. The relay serves as an automatic switch as when the output is obtained the control switches over to the main power supply. This model uses a single channel relay module connected to the Arduino. The controller is programmed with actual time and load shedding time. Both real time and load shedding time can be monitored using the monitor. Program checks whether the target time equals the real time. The output relay gets turns OFF when the values are not equal and turns ON, as target time equals the real time values as shown in Figure 8 and Figure 9.

\begin{tabular}{|c|c|c|}
\hline No. & Name of the Component & Quantity \\
\hline 1 & Arduino Uno Board & 1 \\
\hline 2 & Real Time Clock & 1 \\
\hline 3 & Matrix Keypad & 1 \\
\hline 4 & Relay Driver IC & 1 \\
\hline 5 & Lamp & 1 \\
\hline
\end{tabular}

\section{SIMULATION RESULTS}

The simulation of load shedding and circuit breaker operation is done using PSCAD soft-ware. The drastic change in current and voltage during the circuit breaker operation is observed in the three phase circuit. The single line diagram of the simulation of two bus system is repre-sented in Figure 8 . The transients in voltage and current are observed during the circuit breaker operation as shown in Figure 9. The three phase three bus system simulation is done to observe the circuit breaker operation and its effect in the current and bus voltages. The simulation of three phase three bus system is represented in Figure 10. The graphical observation of current and voltages are represented in Figure 11. 


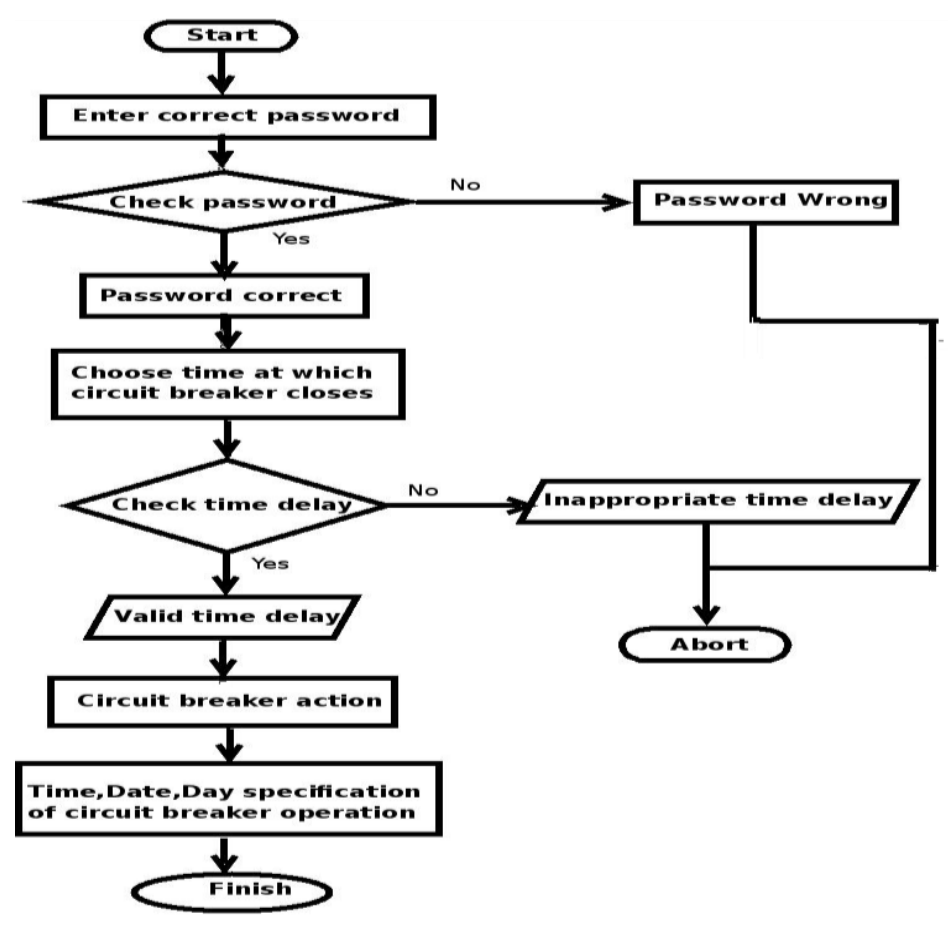

Figure 6. Logical representation of circuit breaker monitoring system

\section{IOT BASED CENTRAL PROTECTION SYSTEM}

A fully automated IoT based Central Protection System (CPC) is proposed for protecting the Microgrid. It not only detects and clears the faults but also ensures the accuracy of the mea-sured parameters. It serves as the main control centre and configures the relay operation. It is a communication based protection system that shield the MG from problems like false tripping, unwanted islanding, sympathetic tripping etc., which demand immediate attention. Therefore, it is important for the CPC to perform autonomously. Implementing the system online mitigates many challenges like the cost and space requirements. The desirable qualities of the proposed system are data acquisition from current and voltage transformers (data are mainly bus voltages and cur-rents), wired or wireless data transfer to cloud, analysis of the collected data and error detection, reconfiguration of the microgrid by receiving signal and trigger the corresponding relays. The data to be collected are current values scaled down by a current transformer within the range (0-5)A. The data is then sent to a microcontroller using a Data Acquisition Card with the help of inbuilt ADCs. As seen in Figure 12, the captured data is then stored in a server that enables visualisation of data in graphical form that allows the user to view rate of change of parameters. A threshold value is set for the parameters, exceeding which a trigger signal is sent to the Microcontroller Unit (MCU) which generates a response based on the type of fault. An Adaptive Protection Scheme is introduced. The following responses are generated by the MCU:

a. In case of a ground fault or short circuit at a node, then isolation of the node is done.

b. In case of a fault in the grid, then islanded operation of microgrid is implemented.

c. In case of an over-current fault, the relays in the shortest path connecting the node to the grid are disconnected.

Continuous reconfiguration of the grid makes it difficult to design an effective protection scheme to clear faults. The efficient way to solve this issue is to design a reliable automatic computerized system to monitor all the parameters. The proposed cloud based system is cost efficient and reduces the required manpower. Authorities are notified of any issue via SMS alerts to ensure immediate attention. 


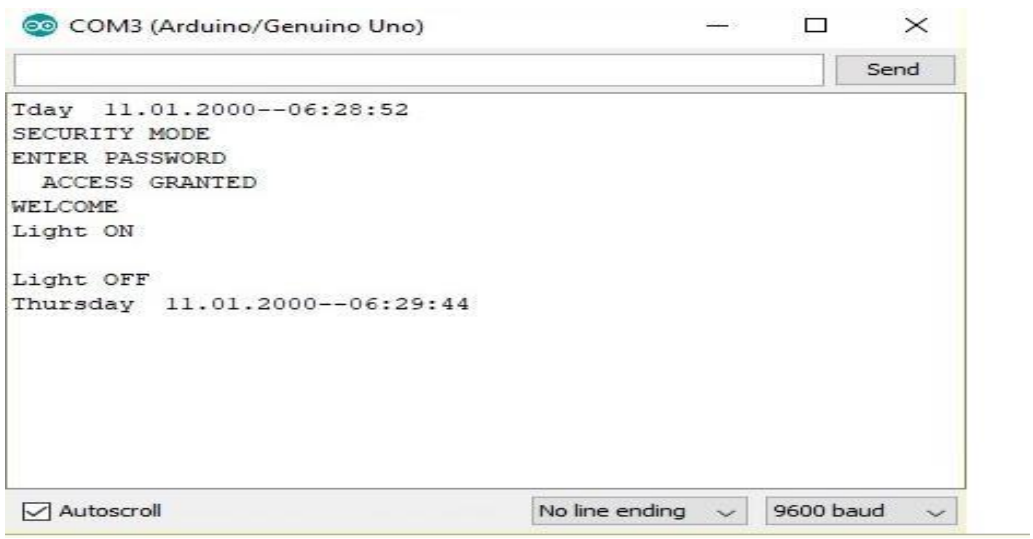

Figure 7. Recording of circuit breaker operation

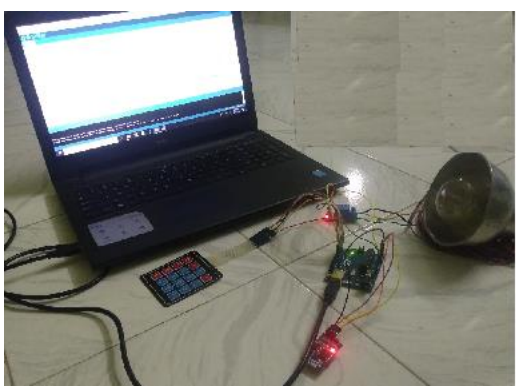

(a)

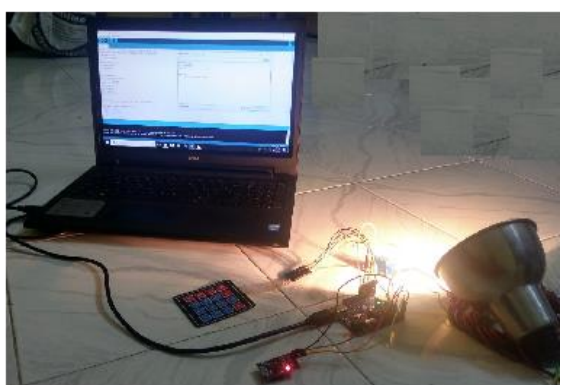

(b)

Figure 8. (a) Load shedding (b) Load is powered at scheduled time

\section{CONCLUSION}

The implemented prototype aids in secured data transfer and circuit breaker operation without human interruption. This type of remote control of circuit breaker operation reduces hu-man effort and enhances safety. The same may be implemented using IoT. The circuit breaker operation of three phase circuits is analysed and observed. The mode of operation of the micro-grid is determined by circuit breaker status which depends on the programmed delay. This method of load shedding process discussed is much more user-friendly than manual operation of circuit breaker. This method of implementation helps in control of electrical systems in substations from far away location. The usage of RTC uses time stamping and time synchronization. Further, IOT based systems could be used in substation automation and expanded with large scale real time equipment. Necessary actions could be taken to protect the grid from further damage.

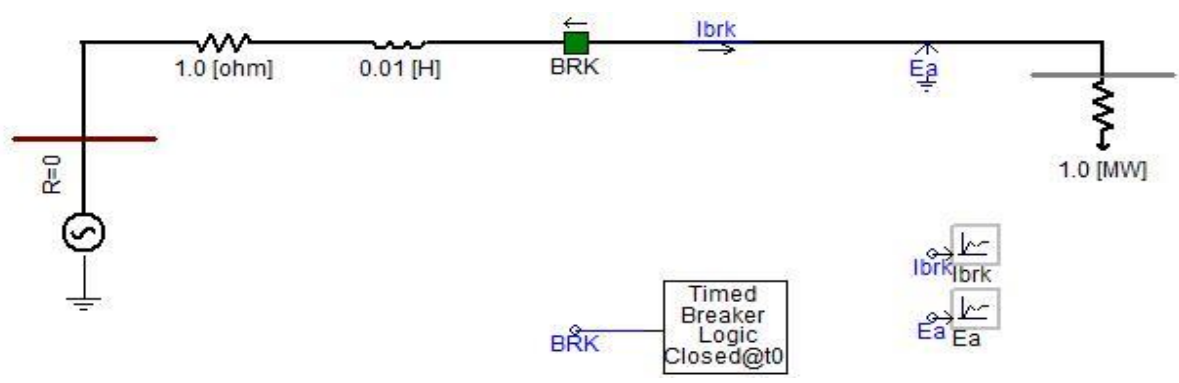

Figure 9. Two bus system simulation 

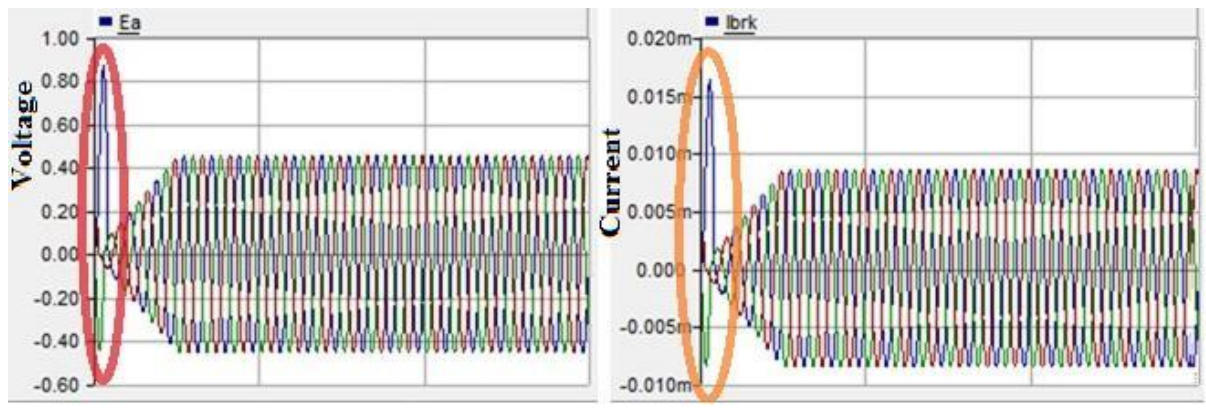

Figure 10. Transients during the circuit breaker in three phase system

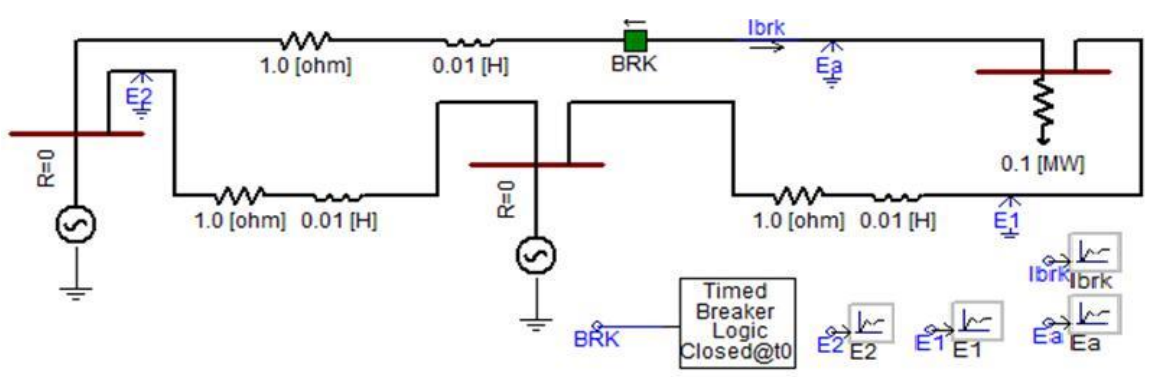

Figure 11. Three phase three bus systems

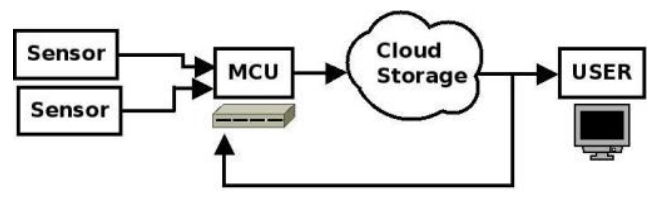

Figure 12. Flow of data in a CPC [22]

This method of controlling allows the operator to control the field equipment from remote location. The fault or the operation is recorded with time stamp allows the user to view the trends of the power system for future analysis and estimates. The password protection system helps in data security and avoids interruption of third party. Loads are shedded using preferential load shedding scheme, determining the critical and non-critical loads during the crisis period. Thus the proposed work helps in monitoring, controlling and operating the circuit breaker from remote areas without manual interruption and with an automated protective security system.

\section{REFERENCES}

[1] Nur Najihah Abu Bakar, Mohammad Yusri Hassan, Mohamad Fani Sulaima, Mohamad Naim Mohd Nasir, Aziah Khamis," Microgrid and load shedding scheme during islanded mode: A review," Elsevier Renewable and sustainable energy reviews, pp.161-169, 2017.

[2] Pecas Lopes JA, Moreira CL, Madureira AG," Dening control strategies for microgrids is-landed operation,"IEEE Trans Power System, Vol 21,2006.

[3] Katiraei F," Microgrids management,"IEEE Power Energy Magazine Vol 6 issue:3, pp.5465, 2008.

[4] Murari Lal Azad AK, Vikram Singh Shubhranshu," Operation and control of micro sources in island mode of a microgrid,"Int J Innov Technol Explor Eng (IJITEE) Vol 4, issue(3), 2014.

[5] Jaisudha S., Sowmiya Srinivasan, Kanimozhi G, Bidirectional Resonant DC-DC converter for Microgrid Applications, International Journal of Power Electronics and Drives Systems (IJPEDS), Vol.8, No.4, pp- 1548-1561, Dec 2017.

[6] Murari Lal Azad AK, Vikram Singh Shubhranshu," Operation and control of micro sources in island mode of a microgrid”, Int J Innov Technol Explor Eng, vol 4, issue 3, 2014. 
[7] Ringler P, Keles D, Fichtner W,"Agent-based modelling and simulation of smart electricity grids and marketsA literature review,".Renew Sustain Energy Rev vol.57, pp-205-215, 2016.

[8] Bharathi GJ, Sait HH,"Power balanced load shedding of microgrid systems using nonlinear system stabilizer", In: Proceedings of the International Conference on Advances in Engineer-ing and Technology,2014.

[9] Mi Y. et al," The fuzzy droop control design for storage system of DC microgrid", In: Proceed-ings of the Chinese Control and Decision Conference (CCDC), 2016.

[10] Mohammad Ghaderi Darebaghi, Turaj Amraee," Dynamic multi-stage under frequency load shedding considering uncertainty of generation loss", IET Generation, Transmission and Dis-tribution, vol.11, issue 13, pp-3202 - 3209, 2017.

[11] Hsu C, Kang M, Chen C," Design of adaptive load shedding by articial neural networks", In: Proceedings of the IEEE Generation, Transmission and Distribution, 2005.

[12] Zhang L, Zhong J, "UFLS Design by Using $f$ and Integrating $d f / d t$ ", In: Proceedings of the IEEE Power Systems Conference and Exposition, PSCE'06, PES, 2006.

[13] Omar Y, et al," Under frequency load shedding (UFLS): Principles and implementation",In: Proceedings of the IEEE International Conference on Power and Energy (PECon), 2010.

[14] Parniani M, Nasri A,"SCADA based under frequency load shedding integrated with rate of frequency decline", In: Proceedings of the IEEE Power Engineering Society General Meeting, 2006.

[15] Grewal GS, Konowalec JW, Hakim M,"Optimization of a load shedding scheme",IEEE Ind Appl Mag vol.4(4), pp.25 -30, 1998.

[16] Haval Sardar Kamil, Dalila Mat Said, Mohd Wazir Mustafa, Mohammad Reza Miveh, Nasarudin Ahmad," Lowvoltage Ride-through Methods for Grid-connected Photovoltaic Sys-tems in Microgrids: A Review and Future Prospect," vol.9(4),pp. 1834-1841,2018.

[17] Yong M, et al," Analysis of power-frequency dynamics and designation of under frequency load shedding scheme in large scale multi-machine power systems", In:Proceedings of the International Conference on IEEE Advances in Power System Control, Operation and Man-agement,1991.

[18] Anderson PM, Mirheydar M,"An adaptive method for setting underfrequency load shedding relays", IEEE Trans Power Syst, Vol.7 issue 2, pp-647655, 1992.

[19] Anay Majee, Gnana Swathika O.V, "IOT based Central Protection Centre for Reconfigurable Microgrids",International Journal of Pure and Applied Mathematics, pp-11-18, 2018.

[20] Ibrahim Alhamrouni, M. A. Hairullah, N. S. Omar, Mohamed Salem, Awang Jusoh, T. Sutikno. Modelling and Design of PID controller for voltage control of AC Hybrid Micro-grid, IAES International Journal of Power Electronics and Drives System (IJPEDS), vol 10 no.1, 2019. pp 151-159.

[21] Abdelhafid Yahya, Hassan El Fadil, Mustapha Oulcaid. Output Feedback Nonlinear Control of Three-Phase GridConnected PV Generator, IAES International Journal of Power Electronics and Drives System (IJPEDS), vol.10, No.1, pp 137-150,2019.

[22] Manohar B S, Banakara Basavaraja. ANFIS based Hybrid Solar and Wave Generator for Distribution Generation to Grid Connection. IAES International Journal of Power Electronics and Drives System (IJPEDS), Vol 10 no.1 pp 179-185, 2019. 